Original Article

\title{
Effects of using an unstable inclined board on active and passive ankle range of motion in patients with ankle stiffness
}

\author{
WON-GYU Yoo ${ }^{1)}$ \\ 1) Department of Physical Therapy, College of Biomedical Science and Engineering, Inje University: \\ 607 Obangdong, Gimhae, Gyeongsangnam-do 621-749, Republic of Korea
}

\begin{abstract}
Purpose] The present study assessed the effects of using an unstable inclined board on the active and passive ankle range of motion in patients with ankle stiffness. [Subjects] The study included 10 young female patients with ankle stiffness. [Methods] The patients were divided into the following two groups: a group that performed ankle dorsiflexion stretching exercises using a wooden inclined board and a group that performed stretching exercises using an air-cushioned inclined board (unstable inclined board). Active and passive ankle dorsiflexion angles were measured bilaterally using a goniometer. [Results] Both inclined boards significantly increased active and passive ankle dorsiflexion. After performing ankle stretching exercises, active dorsiflexion significantly increased the unstable inclined board compared to that using the wooden inclined board. However, the passive dorsiflexion angles did not differ significantly between the two groups after ankle stretching exercises. [Conclusion] The use of an unstable inclined board might stimulate activation of the ankle dorsiflexors in addition to stretching muscle or tissue. Active ankle dorsiflexion was more effectively improved with stretching exercises using an unstable inclined board than with exercises using a wooden inclined board.

Key words: Inclined board, Stretching exercise, Unstable surface
\end{abstract}

(This article was submitted Mar. 13, 2015, and was accepted Apr. 16, 2015)

\section{INTRODUCTION}

Musculoskeletal stiffness and limited range of motion (ROM) can restrict functional joint movement, particularly during ankle supination following neurological diseases ${ }^{1)}$. Ankle dorsiflexion ROM restrictions impair dynamic balance and gait, which may contribute to secondary injuries; reduced ankle ROM and tight calf muscles can cause poor gait, inefficient energy use, impaired balance, and an increased risk of falls ${ }^{2}$. Musculoskeletal transformations manifesting as abnormal joint stiffness and limited ROM result in numerous restrictions in the function and joint movements of patients ${ }^{3)}$. Limited passive ankle dorsiflexion ROM during knee extension can alter foot positioning and result in compensatory foot movements, leading to an abnormal gait, which can result in ankle sprains and lower extremity overuse injuries ${ }^{4}$. Studies have reported that balancetraining programs that alter the somatosensory input, such as the use of an unstable surface to induce equalized weight distribution, can be helpful in hemiplegic patients ${ }^{5)}$. Kim et al. used an ankle board with a slope in their center to achieve

Corresponding author. Won-gyu Yoo (E-mail: won7y@inje. ac.kr)

C2015 The Society of Physical Therapy Science. Published by IPEC Inc. This is an open-access article distributed under the terms of the Creative Commons Attribution Non-Commercial No Derivatives (by-ncnd) License $<$ http://creativecommons.org/licenses/by-nc-nd/3.0/>. efficient ankle stretching and increased dorsiflexion ${ }^{6}$. They suggested that stretching exercises using their device resulted in a greater increase in foot pressure compared to that with stretching exercises using existing inclined boards during ankle dorsiflexion stretching ${ }^{6}$. Therefore, we investigated the effects of an unstable inclined board on the active and passive ankle ROM in patients with ankle stiffness.

\section{SUBJECTS AND METHODS}

The study included 10 female patients (mean age, 22.8 \pm 5.3 years; height, $158.9 \pm 3.0 \mathrm{~cm}$; weight, $61.2 \pm 4.7 \mathrm{~kg}$ ) with ankle stiffness caused by diseases or medical conditions. The patients were selected based on ankle stiffness scores obtained using a symptom checker tool. The patients were assigned randomly to two groups (both $\mathrm{n}=5$ ) and their height and weight were measured. The patients were not cognitively impaired and were capable of independent walking for $20 \mathrm{~m}$ without difficulty. Patients were excluded if they had a history of or current neurological conditions. Before participating, the purpose and methods of the study were explained to the patients, and all provided informed consent, according to the principles of the Declaration of Helsinki.

Active and passive ankle dorsiflexion were measured using a standard $31.75 \times 4.45 \mathrm{~cm}$ clear plastic goniometer, with one increment, a $360^{\circ}$ scale, and a bubble level at each end. Group 1 performed the ankle dorsiflexion stretching exercise using a wooden inclined board, and group 2 performed ankle 
dorsiflexion stretching exercises using an air-cushioned inclined board that provided an unstable surface. Both inclined boards were set to an approximately $15^{\circ}$ tilt. Rubber sheets were attached to the inclined boards to prevent falls due to sliding. The patients performed ankle dorsiflexion stretching exercises for $5 \mathrm{~min}$, with a 10 -min rest between each set, five times a day for 1 week. The active and passive ankle dorsiflexion angles were measured bilaterally using the goniometer before and after the study.

Independent and paired t-tests were used to assess withinand between-group differences in ankle dorsiflexion, with SPSS for Windows (SPSS, Chicago, IL, USA). A p-value < 0.05 was considered to indicate statistical significance.

\section{RESULTS}

The amount of active and passive dorsiflexion did not differ between the two groups before the exercises, with active dorsiflexion angles of $18.2 \pm 6.4^{\circ}$ and $19.3 \pm 4.2^{\circ}$ and passive dorsiflexion angles of $23.4 \pm 5.5^{\circ}$ and $22.6 \pm 5.7^{\circ}$ in groups 1 and 2 , respectively (both $\mathrm{p}>0.05$ ). The stretching exercises significantly $(\mathrm{p}<0.05)$ increased the active and passive ankle dorsiflexion angles in both groups compared to those at baseline. The active dorsiflexion angle was significantly increased $(p<0.05)$ in group 2 compared to that in group 1 after the exercises. The active dorsiflexion angles before and after the exercises were $18.2 \pm 6.4^{\circ}$ and $22.1 \pm$ $5.0^{\circ}$ in group 1 and $19.3 \pm 4.2^{\circ}$ and $28.1 \pm 6.9^{\circ}$ in group 2, respectively. The passive dorsiflexion angles did not differ significantly between the groups after the exercises $(\mathrm{p}>0.05)$ and were $23.4 \pm 5.5^{\circ}$ and $32.2 \pm 5.3^{\circ}$ in group 1 and $22.6 \pm$ $5.7^{\circ}$ and $35.1 \pm 6.0^{\circ}$ in group 2 before and after exercising, respectively.

\section{DISCUSSION}

This study developed a new inclined board for ankle dorsiflexion stretching. The air-cushioned inclined board provided an unstable surface for performing ankle dorsiflexion stretching exercises. The results showed that ankle stretching exercises using the unstable inclined board significantly increased the active dorsiflexion angle compared to that with exercises using a wooden inclined board. We believe that the use of the air-cushioned inclined board provides somatosensory input and subsequently stimulates active ankle dorsiflexion by promoting automatic postural control. Sensory proprioception of the ankle and sensory compression of the plantar are important in the control of sway ${ }^{7}$. An increase in the number of somatosensory inputs affects the muscles, and the use of an unstable support surface result in many different somatosensory inputs that limit compensatory action ${ }^{7}$. Performing cognitive tasks in a standing posture reduces internal focus and induces external focus, which promotes automatic postural control ${ }^{8)}$. Stretching improve the flexibility of tendons, and changes in the mechanical condition of tendons depend on the type of stretching performed ${ }^{9}$. Stretching exercises can reduce spasticity by increasing tissue flexibility ${ }^{9}$.

In this study, the passive dorsiflexion angles did not differ significantly between the two groups after ankle stretching exercises. However, stretching exercises significantly increased the active and passive ankle dorsiflexion angles in both groups compared to those at baseline. These results suggest that passive ankle exercises using a wooden inclined board only stretch muscle and tissue, while exercises using an unstable inclined board stretch muscle and tissue, and stimulate activation of the ankle dorsiflexor. Active ankle dorsiflexion was more effectively improved with ankle stretching exercises using an unstable inclined board than with exercises using a wooden inclined board.

\section{REFERENCES}

1) Hoch MC, Staton GS, Medina McKeon JM, et al.: Dorsiflexion and dynamic postural control deficits are present in those with chronic ankle instability. J Sci Med Sport, 2012, 15: 574-579. [Medline] [CrossRef]

2) Drewes LK, McKeon PO, Kerrigan DC, et al.: Dorsiflexion deficit during jogging with chronic ankle instability. J Sci Med Sport, 2009, 12: 685-687. [Medline] [CrossRef]

3) Patla AE, Prentice SD: The role of active forces and intersegmental dynamics in the control of limb trajectory over obstacles during locomotion in humans. Exp Brain Res, 1995, 106: 499-504. [Medline] [CrossRef]

4) Willems TM, Witvrouw E, Delbaere K, et al.: Intrinsic risk factors for inversion ankle sprains in male subjects: a prospective study. Am J Sports Med, 2005, 33: 415-423. [Medline] [CrossRef]

5) Taube W, Gruber M, Beck S, et al.: Cortical and spinal adaptations induced by balance training: correlation between stance stability and corticospinal activation. Acta Physiol (Oxf), 2007, 189: 347-358. [Medline] [CrossRef]

6) Kim TK, Yoo WG, Shin SJ: Comparison of foot pressure in stretching exercises according to the type of ankle ramp. J Phys Ther Sci, 2015, 27 : 455-456. [Medline] [CrossRef]

7) Chiang $\mathrm{JH}, \mathrm{Wu} \mathrm{G}$ : The influence of foam surfaces on biomechanical variables contributing to postural control. Gait Posture, 1997, 5: 239-245. [CrossRef]

8) Huxhold O, Li SC, Schmiedek F, et al.: Dual-tasking postural control: aging and the effects of cognitive demand in conjunction with focus of attention. Brain Res Bull, 2006, 69: 294-305. [Medline] [CrossRef]

9) Mahieu NN, McNair P, De Muynck M, et al.: Effect of static and ballistic stretching on the muscle-tendon tissue properties. Med Sci Sports Exerc, 2007, 39: 494-501. [Medline] [CrossRef] 